\title{
A seasonal energy-balance climate model for coupling to ice-sheet models
}

\author{
ANdré PAUl \\ Fachbereich Geowissenschaften, Universität Bremen, D-28334 Bremen, Germany
}

\begin{abstract}
An energy-balance climate model designed for coupling to ice-sheet models is presented. Its independent variables are longitude, latitude and time of the year. The model is based on the vertically integrated equations of conservation of energy and humidity. It can predict the vertically averaged temperature. Since it includes a hydrological cycle, it can also diagnose the net fresh-water flux and hence the annual snow budget at the atmosphere-ice-sheet interface. To this end, the model does not require observed precipitation rates. The computational cost is reduced by using an analytically computed Fourier-Legendre representation of daily insolation. For a highly idealized test-case configuration, two simple sensitivity experiments are carried out.
\end{abstract}

\section{INTRODUGTION}

To study the Pleistocene ice ages, it is desirable to use a global coupled climate ice-sheet model. Unfortunately, a general circulation model is very expensive to run. It does not permit extensive sensitivity experiments and often its results are difficult to interpret. Therefore, an atmospheric model is needed which contains the essential feedback mechanisms that affect the growth and decay of ice sheets but it takes a much smaller amount of additional computing time and is easier to interpret. As has been suggested by Pollard (1983), Esch and Herterich (1990) and Deblonde and Peltier (1991), these requirements seem to be met by an energy-balance climate model.

Therefore, a global, two-dimensional, vertically integrated energy-balance climate model is presented. It is solved by the spectral method in space and time. The horizontal resolution is T16 and the seasonal and semiseasonal variations are included. The land sea distribution and the albedo can be specified arbitrarily.

Although the model is quite similar to those of Hyde and others (1989) and Deblonde and Peltier (1991), it differs from them in three important respects. First, the model does not use observed precipitation rates which may change considerably on the time-scale of the ice ages. It rather employs a simple parameterization of the evaporation of water, transport of water vapour and its precipitation, based on the ideas of Pollard (1983), Sanberg and Oerlemans (1983) and Bowman (1985). Secondly, to reduce the computational cost, the model takes advantage of an analytically computed FourierLegendre representation of daily insolation. Thirdly, the coefficients which couple the spectral modes of the different fields together are evaluated recursively (Schulten and Gordan, 1975, 1976).

In the present version, the model is linear in that the sea-ice extent does not depend on temperature. To investigate its behaviour, a test case is studied which is based on the highly idealized land-sea distribution proposed by Pollard (1983). Two simple sensitivity experiments are carried out which show the effect of varying the size of an ice sheet on the global annual mean temperature.

\section{MODEL DESCRIPTION}

\subsection{Basic equations}

The vertically integrated equations of conservation of energy and humidity may be cast into the form (cf. Jentsch, 1991)

$$
\begin{gathered}
\frac{\partial}{\partial t}(C T)=-\nabla \cdot \mathbf{F}+X \\
\frac{\partial}{\partial t}\left(L_{\mathrm{v}} W\right)=-\nabla \cdot \mathbf{F}_{\mathrm{q}}+X_{\mathrm{q}} .
\end{gathered}
$$

where $T$ is the sea-level air temperature in ${ }^{\circ} \mathrm{C}$ and $W$ is the amount of water vapour in an atmospheric column extending from the surface to the top of the atmosphere. The sea-level air temperature can be formally related to the vertically integrated temperature by setting

$$
\rho H T=\int \rho^{\prime}(z) T^{\prime}(z) \mathrm{d} z .
$$

Here, $\rho$ is taken to be a constant surface-air density over land and a constant mixed-layer density over ocean; $H$ is the effective height of the atmosphere ocean column considered, which may well differ from its actual height. Furthermore, $\rho^{\prime}$ denotes the height-dependent density and $T^{\prime}$ the height-dependent temperature of this column.

On the lefthand side of Equations (1) and (2), CT and $L_{\mathrm{v}} W$ denote, respectively, the vertically integrated 
sensible heat of atmosphere and ocean and the vertically integrated latent heat of the atmosphere alone. Here, $C \approx c_{\mathrm{p}} \rho H$ and $L_{\mathrm{v}}$ play the role of inertia coefficients with $c_{\mathrm{p}}$ being the specific heat at constant pressure, while $L_{\mathrm{v}}$ is the latent heat of vaporization.

Following North and others (1983) and Hyde and others (1989), the thermal inertia coefficient $C$ is given a large value $C_{\mathrm{w}}$ over the ocean, a smaller value $C_{\mathrm{si}}$ over sea ice and a very small value $C_{1}$ over land. In the first case, it is taken to represent the heat capacity of an ocean mixed layer with an average depth $H_{\mathrm{w}}=75 \mathrm{~m}$, while in the third case it stands for the heat capacity of an atmospheric layer with effective upper boundary $H_{\mathrm{a}}=4.2 \mathrm{~km}$. Hence, $C_{\mathrm{W}}=9.7 \mathrm{~W} \mathrm{a} \mathrm{m}^{-2}{ }^{\circ} \mathrm{C}^{1}, C_{\mathrm{si}}=0.75 \mathrm{~W} \mathrm{a} \mathrm{m}^{-2}{ }^{\circ} \mathrm{C}^{-1}$ and $C_{\mathrm{l}}=$ $0.165 \mathrm{~W} \mathrm{a} \mathrm{m}^{-2} \mathrm{C}^{-1}$.

On the righthand side of Equations (1) and (2), $F$ and $F_{\mathrm{q}}$ denote the fluxes of heat and water vapour, and $X$ and $X_{\mathrm{q}}$ represent the diabatic terms which are given by

$$
\begin{aligned}
X & =R_{\mathrm{i}}-R_{o}, \\
X_{\mathrm{q}} & =L^{*} E-L_{\mathrm{v}} P
\end{aligned}
$$

where $R_{\mathrm{i}}$ and $R_{o}$ are the incoming and outgoing radiative fluxes at the top of the atmosphere, while $E$ and $P$ denote evaporation and precipitation. The latent heat of the phase change of water is $L^{*}=L_{\mathrm{v}}=2.5008 \times 10^{6} \mathrm{~J} \mathrm{~kg}^{-1}$ for vaporization and $L^{*}=L_{\mathrm{s}}=2.8345 \times 10^{6} \mathrm{Jkg}^{-1}$ for sublimation.

All fields in Equations (1) and (2) depend on longitude $\lambda$, latitude $\phi$ and time $t$ in the year. Often $\mu=\sin \phi$ is used rather than $\phi$ itself.

\subsection{Radiation}

The incoming short-wave radiation is given by

$$
R_{\mathrm{i}}=\frac{S_{0}}{4} a S
$$

where $S_{0}=1360 \mathrm{~W} \mathrm{~m}^{-2}$ is the solar constant as used by North and others (1983), $a$ is the co-albedo (or one minus the albedo) and $S$ determines the distribution of daily insolation at each latitude and at each time in the year (North and Coakley, 1979). Over ice-free areas, the co-albedo is taken to be a smooth function of latitude

$$
a(\mu)=a_{0}+a_{1} P_{1}(\mu)+a_{2} P_{2}(\mu)
$$

where $P_{n}$ is the $n$ th-order Legendre polynomial and the coefficients $a_{0}=0.679, a_{1}=-0.012$ and $a_{2}=-0.241$ are derived from present-day satellite observations Graves and others, 1993). The discontinuous change in albedo in the presence of snow cover over land areas or sea-ice cover over ocean areas is represented by the albedo jumps $\Delta a_{\mathrm{su}}=-0.14$ and $\Delta a_{\mathrm{si}}=-0.07$. Over land, ice-covered areas, a constant value $a_{\mathrm{li}}=0.3$ is used (Deblonde and Peltier, 1991).

According to Budyko (1969), the outgoing long-wave radiation can be parameterized as

$$
R_{o}=A+B(T-\gamma h)
$$

where the constants $A=205 \mathrm{Wm}^{2}$ and $B=1.9 \mathrm{Wm}^{2}$ ${ }^{\circ} \mathrm{C}^{-1}$ are taken from Pollard (1983) and Graves and others
(1993), respectively. The term $-B \gamma h$ accounts for the negative feedback of cold, elevated ice-sheet surfaces on the temperature (Bowman, 1982); $\gamma=6.5 \mathrm{~K} \mathrm{~km}^{-1}$ is a constant lapse rate (Pollard, 1983) and $h$ denotes the icesheet surface elevation above sea level.

\subsection{Heat transport}

In Equation (1), the transport of heat in the atmosphere ocean system is given by the divergence of the vertically integrated heat flux $F$. The explicit form of the horizontal divergence operator in spherical coordinates is

$$
\nabla \cdot=\frac{1}{R_{\mathrm{E}}} \frac{\partial}{\partial \mu}\left(1-\mu^{2}\right)^{\frac{1}{2}}+\frac{1}{R_{\mathrm{E}}\left(1-\mu^{2}\right)^{\frac{1}{2}}} \frac{\partial}{\partial \lambda}
$$

where $R_{\mathrm{E}}=6.37122 \times 10^{6} \mathrm{~m}$ is the radius of the Earth. The various kinds of heat transport are simulated by a diffusion process. Hence, they are taken to be proportional to the negative of the sea-level temperature gradient

$$
F=-K\left[\left(1-\mu^{2}\right)^{\frac{1}{2}} \frac{\partial T}{\partial \mu}+\frac{\kappa^{2}}{\left(1-\mu^{2}\right)^{\frac{1}{2}}} \frac{\partial T}{\partial \lambda}\right]
$$

where

$$
D=\frac{K}{R_{\mathrm{E}}}=D_{0}\left(1+D_{2} \mu^{2}+D_{4} \mu^{4}\right)
$$

is the effective diffusivity for sensible heat, $K$, divided by the radius of the Earth, $R_{\mathrm{E}}$. Here, the latitude-dependence of $D$ is based on the argument that the tropical Hadley cells are much more efficient at smoothing temperature anomalies than the mid-latitude eddies (North and others, 1983). Hence, $D$ is assumed to be three times as large at the Equator as at the poles (see Table 1). The constant $\kappa$ determines the degree of anisotropy of the diffusion process; in this study, it is set to 1 .

\subsection{Precipitation, evaporation and snow budget}

The parameterization of mid-latitude precipitation and evaporation is that of Sanberg and Oerlemans (1983)

$$
\begin{gathered}
E=\left(W_{\max }-W\right) / \tau \\
P=\left(f_{0}+f_{1} S\right) W
\end{gathered}
$$

where $W_{\max }$ is the maximum value of the moisture content $W$ in the atmospheric column. Evaporation $E$ is taken to depend on a characteristic time $\tau$, which is the time-scale on which the atmosphere tends to become saturated; it is estimated as $\tau_{\mathrm{w}}=3 \mathrm{~d}$ over water, $\tau_{\mathrm{l}}=6 \mathrm{~d}$ over land and $\tau_{\mathrm{li}}=30 \mathrm{~d}$ over ice sheets. Precipitation $P$ is proportional to the moisture content $W$ and consists of some background precipitation $f_{0} W$ and the upslope precipitation $f_{1} S W$, where $S$ is the upwind slope of the ice-sheet surface in percent. Furthermore, $f_{0}=0.188 \mathrm{~s}^{-1}$ and $f_{1}=0.353 \mathrm{~s}^{-1}$.

Integrating the saturation absolute humidity $\rho_{\mathrm{s}}$ over an atmospheric column of height $H_{\mathrm{q}}$, using a heightdependent density $\rho_{a}^{\prime}$ but a constant lapse rate $\gamma, W_{\max }$ can be obtained as a function of sea-level temperature $T$ and elevation $h$. If one neglects the change of the latent heat of vaporization $L_{\mathrm{v}}$ with pressure, one gets the 
Table 1. Values, units and sources of the model parameters

Para- Value Units Source
meter

\begin{tabular}{|c|c|c|}
\hline$S_{0}$ & $1360 \mathrm{~W} \mathrm{~m}^{-2}$ & North and others (1983) \\
\hline$A$ & $205 \mathrm{~W} \mathrm{~m}^{-2}$ & Pollard (1983) \\
\hline$B$ & $1.9 \mathrm{~W} \mathrm{~m}^{2}{ }^{\circ} \mathrm{C}^{-1}$ & Graves and others (1993) \\
\hline$C_{\mathrm{w}}$ & $9.7 \mathrm{~W} \mathrm{a} \mathrm{m}^{-2}{ }^{\circ} \mathrm{C}^{-1}$ & Hyde and others (1989) \\
\hline$C_{\mathrm{si}}$ & $0.75 \mathrm{~W} \mathrm{a} \mathrm{m}^{-2}{ }^{\circ} \mathrm{C}^{-1}$ & Hyde and others (1989) \\
\hline$C_{1}$ & $0.165 \mathrm{~W} \mathrm{a} \mathrm{m}^{-2}{ }^{\circ} \mathrm{C}^{-1}$ & Hyde and others (1989) \\
\hline$D_{0}$ & $1.5 \mathrm{~W} \mathrm{~m}^{-2 \circ} \mathrm{C}^{-1}$ & This study \\
\hline$D_{2}$ & -1.330 & Hyde and others (1989) \\
\hline$D_{4}$ & 0.670 & Hyde and others (1989) \\
\hline$a_{0}$ & 0.679 & Graves and others (1993) \\
\hline$a_{1}$ & -0.012 & Graves and others (1993) \\
\hline$a_{2}$ & -0.241 & Graves and others (1993) \\
\hline$\Delta a_{\mathrm{sn}}$ & -0.14 & Graves and others (1993) \\
\hline$\Delta a_{\mathrm{si}}$ & -0.07 & Graves and others (1993) \\
\hline$a_{\mathrm{li}}$ & 0.3 & Deblonde and Peltier (1991) \\
\hline$\tau_{\mathrm{w}}$ & $3 \mathrm{~d}$ & Sanberg and Oerlemans (1983) \\
\hline$\tau_{1}$ & $6 \mathrm{~d}$ & Sanberg and Oerlemans (1983) \\
\hline$\tau_{\mathrm{li}}$ & $30 \mathrm{~d}$ & Sanberg and Oerlemans (1983) \\
\hline$f_{0}$ & $0.188 \mathrm{~s}^{-1}$ & Sanberg and Oerlemans (1983) \\
\hline$f_{1}$ & $0.353 \mathrm{~s}^{-1}$ & Sanberg and Oerlemans (1983) \\
\hline$H_{\mathrm{q}}$ & $8.0 \mathrm{~km}$ & This study \\
\hline$\gamma$ & $6.5^{\circ} \mathrm{C} \mathrm{km}^{-1}$ & Pollard (1983) \\
\hline$a$ & 10.0 & Pollard (1983) \\
\hline$b$ & 0.2 & Pollard (1983) \\
\hline$c$ & -70.0 & Pollard (1983) \\
\hline
\end{tabular}

approximate result

$$
\begin{aligned}
W_{\max }(T, h)= & \frac{e\left(T_{0}\right)}{\gamma R_{\mathrm{v}}} \exp \left[\frac{L_{\mathrm{v}}}{R_{\mathrm{v}} T_{0}}\right] \\
& \times\left[\operatorname{Ei}\left(-\frac{L_{\mathrm{v}}}{R_{\mathrm{v}}\left(T-\gamma H_{\mathrm{q}}\right)}\right)\right. \\
& \left.-\operatorname{Ei}\left(-\frac{L_{\mathrm{v}}}{R_{\mathrm{v}}(T-\gamma h)}\right)\right]
\end{aligned}
$$

where $e\left(T_{0}\right)=610 \mathrm{~Pa}$ is the saturation vapour pressure at $T_{0}=0^{\circ} \mathrm{C}$ and $R_{\mathrm{v}}=461.5 \mathrm{~J} \mathrm{~kg}^{-1} \mathrm{~K}^{-1}$ is the gas constant for moist air. The function $\mathrm{Ei}$ is the exponential integral (Press and others, 1992). The upper boundary of the atmosphere for moisture is taken to be approximately $H_{\mathrm{q}}=8 \mathrm{~km}$ high.

Assuming that the rate of change of the atmospheric latent-heat content is small compared to the net evaporation (Bowman, 1985; Chen and others, 1993), the equation of conservation of moisture Equation (2) reduces to a diagnostic relation for moisture content $W$, where

$$
W=\frac{-\nabla \cdot \mathbf{F}_{\mathrm{q}}+L^{*} W_{\max } / \tau}{L^{*} / \tau+L_{\mathrm{v}}\left(f_{0}+f_{1} S\right)}
$$

Now, the moisture content can be related to the temperature through the relative humidity $\chi$, $W=\chi W_{\max }$, where $\chi=0.8$ is used. Approximating the flux of moisture, like that of heat, by a diffusion process, one gets

$$
F_{\mathrm{q}}=-K_{\mathrm{q}}\left[\left(1-\mu^{2}\right)^{\frac{1}{2}} \frac{\partial T}{\partial \mu}+\frac{\kappa^{2}}{\left(1-\mu^{2}\right)^{\frac{1}{2}}} \frac{\partial T}{\partial \lambda}\right]
$$

with

$$
D_{\mathrm{q}}=\frac{K_{\mathrm{q}}}{R_{\mathrm{E}}}=\frac{L_{\mathrm{v}} \chi}{C} \frac{\partial W_{\max }}{\partial T} D
$$

being the effective diffusivity for latent heat $K_{\mathrm{q}}$ divided by the radius of the Earth $R_{\mathrm{E}}$.

From Equations (12), (13) and (15), evaporation $E$ and precipitation $P$ can be obtained. The rate of snowfall or accumulation is then simply given by

$$
s\left[\mathrm{~m} \mathrm{month}^{-1}\right]= \begin{cases}P\left[\mathrm{~m} \mathrm{month}^{-1}\right] & \text { if } T_{\mathrm{s}}<0 \\ 0 & \text { if } T_{\mathrm{s}}>0\end{cases}
$$

where $T_{\mathrm{s}}$ is the monthly sea-level temperature, corrected for height. Following Pollard (1983), the rate of snowmelt or ablation can be related to monthly surface-air temperature and insolation by

$$
m\left[\mathrm{~m} \mathrm{month}^{-1}\right]=\max \left(0, a T_{\mathrm{s}}\left[{ }^{\circ} \mathrm{C}\right]+b R_{\mathrm{i}}\left[\mathrm{W} \mathrm{m}^{-2}\right]+c\right)
$$

where $a=10, b=0.2$ and $c=-70$. Finally, the annual net snow-budget $b$ is the difference $(s-m)$ averaged over 1 year.

\subsection{Spectral method}

The method of solving Equation (2.1) is to solve directly for the steady-state seasonal cycle rather than integrate it forward in time (North and others, 1983). This is achieved by expanding all relevant fields into truncated series of spherical harmonics in space and complex exponentials in time:

$$
\psi(\lambda, \mu, t)=\sum_{n=-N}^{N} \sum_{m=-M}^{M} \sum_{l=|m|}^{L(m)} \psi_{l m}^{n} Y_{l m}(\lambda, \mu) \exp (i 2 \pi n t)
$$

where $Y_{l m}(\lambda, \mu)=P_{l}^{\kappa m}(\mu) e^{i m \lambda}$ and $P_{l}^{\kappa m}(\mu)$ are the associated Legendre polynomials, normalized to one. For triangular truncation, $L(m)=M$ and for rhomboidal truncation, $L(m)=|m|+M$ (Washington and Parkinson, 1986). Since the fields are real, the complex-mode amplitudes satisfy the symmetry $\psi_{l,-m}^{-n}=\left(\psi_{l, m}^{n}\right)^{*}$. At present, triangular truncation is used.

The spatial truncation wave number $M$ is 16 for solar forcing $S$ and temperature response $T$ and, to avoid aliasing, 33 for all other fields. Furthermore, the temporal truncation wave number is $N=2$. Substituting the truncated series into Equation (2.1) and applying the integral operator

$$
\frac{1}{2 \pi} \int_{0}^{1} \mathrm{~d} t \int_{-1}^{1} \mathrm{~d} \mu \int_{0}^{2 \pi} \mathrm{d} \lambda P_{l}^{\kappa m}(\mu) \exp (-i m \lambda) \exp (-i 2 \pi n t)
$$

yields a complex system of $(2 N+1)(M+1)(M+2) / 2$ 
linear algebraic equations for triangular truncation and of $(2 N+1)(M+1)^{2}$ linear algebraic equations for rhomboidal truncation. For example, the explicit form of the heat-transport term is

$-\sum_{n_{1}, m_{1}, l_{1}, n_{2}, m_{2}, l_{2}} \delta_{n, n_{1}+n_{2}} G_{l_{1} l_{2} l}^{m_{1} m_{2} m} D_{m_{2} l_{2}}^{n_{2}} T_{l_{1} m_{1}}^{n_{1}}$

$$
\times \frac{1}{2}\left[l(l+1)+l_{1}\left(l_{1}+1\right)-l_{2}\left(l_{2}+1\right)\right]
$$

where the coupling coefficients $G_{l_{1} l_{2} l}^{m_{1} m_{2} m}$ are given in Appendix B.

\section{NUMERICAL IMPLEMENTATION}

All input and output fields can be represented by gridpoint values on Gaussian grids. For solar forcing $S$ and temperature response $T$, the number of grid points in the longitudinal direction is 64 and the number of grid points in the meridional direction is 32 . For all other fields, these numbers are 128 and 64 , respectively. The transformation from physical space to spectral space is performed by a two-dimensional forward Fast Fourier Transform Press and others, 1992) and Gaussian quadrature. In the case of solar forcing, the mode amplitudes are given analytically (see Appendix A). In spectral space, the complex system of linear algebraic equations is solved by LU decomposition (Press and others, 1992). Finally, the transformation from spectral space to physical space is done by computing the sum

$$
\sum_{l=|m|}^{L(m)} \psi_{l m}^{n} P_{l}^{\kappa m}(\mu)
$$

and performing a two-dimensional inverse Fast Fourier Transform. The grid-point values of the normalized associated Legendre polynomials are calculated using recurrence formulae (Belousov, 1962).

\section{SENSITIVITY ANALYSIS}

For analyzing some of the model's behaviour, a test case with highly idealized geometry and orography is studied (Pollard, 1983). In order to capture the dominant effect of land-sea distribution on climate, a continent is assumed which extends from $6^{\circ} \mathrm{S}$ to $74^{\circ} \mathrm{N}$ and covers $180^{\circ}$ of longitude. The sea-ice lines are fixed at their present-day locations in both hemispheres and taken to be at $62^{\circ} \mathrm{S}$ and $66^{\circ} \mathrm{N}$. South of $70^{\circ} \mathrm{S}$ a fixed Antarctic ice sheet is prescribed.

On the northern part of the continent, a onedimensional ice sheet with elliptic profile

$$
h(x)=h_{0} \sqrt{1-(x / R)^{2}}
$$

can exist. Here, $h_{0}$ is the maximum height, $R$ is the halfwidth and $x$ is the distance from the centre. The surface elevation of land not covered by an ice sheet is set to zero.

In Figures 1 and 2, under modern solar forcing and without an ice sheet, the zonally integrated temperature response of the energy-balance climate model is compared

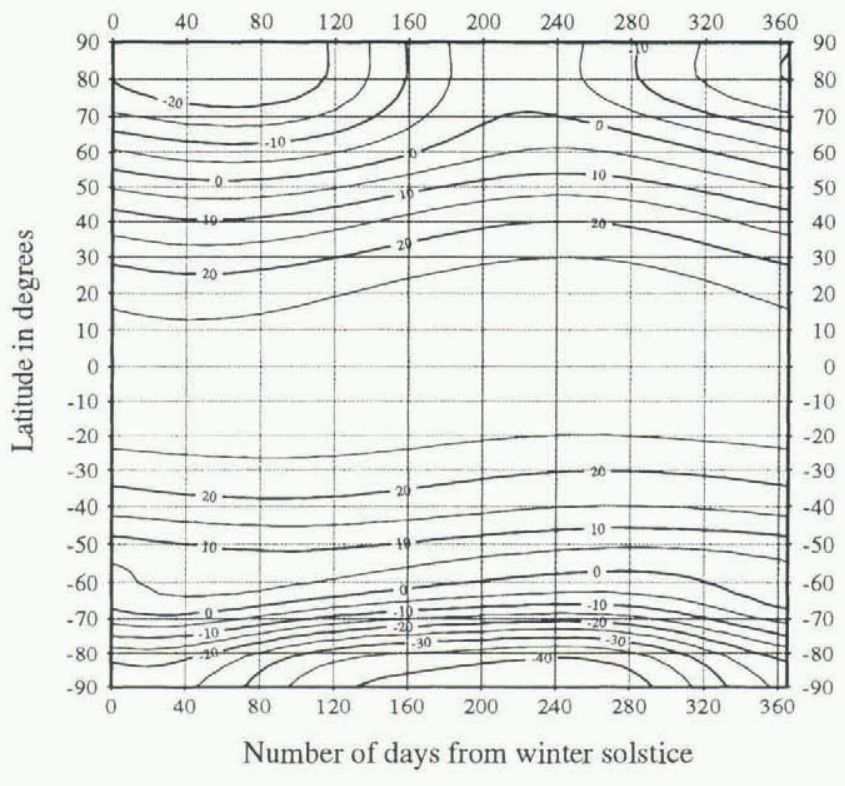

Fig. 1. Zonally averaged sea-level temperature, corrected for height, in ${ }^{\circ} \mathrm{C}$, as simulated by the $T 16$ energy-balance climate model.

with the result from the ECHAM 3 general circulation model at T42 resolution (Roeckner and others, 1992). Although the polar regions are too warm, the energybalance climate model simulates the modern climate reasonably well. But one must bear in mind that any energy-balance climate model is tuned to modern conditions, more so than a general circulation model.

\subsection{Varying maximum height}

In the first sensitivity experiment, the southern-tip position of the Northern Hemisphere ice sheet is fixed at $45^{\circ} \mathrm{N}$ which roughly corresponds to the extent of the Laurentide ice sheet at the Last Glacial Maximum. The maximum height of the ice sheet is varied between 0 and

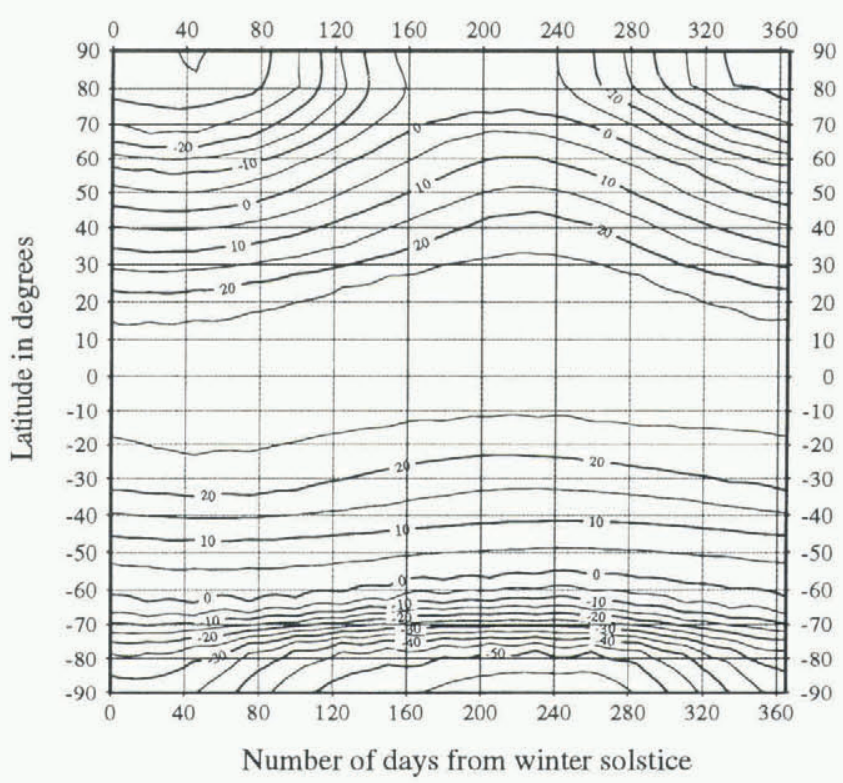

Fig. 2. Zonally averaged $2 m$ lemperature in ${ }^{\circ} \mathrm{C}$, as simulated by the ECHAM 3/T42 global circulation model. 


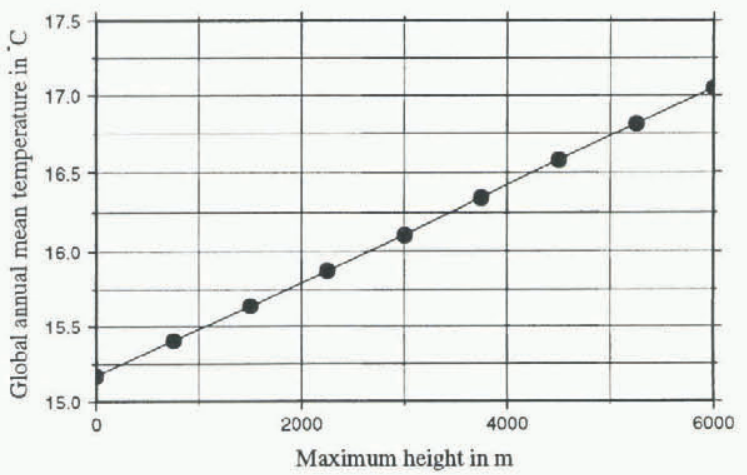

Fig. 3. Global annual mean sea-level temperature versus maximum ice-sheet surface elevation. The ice sheet extends from $72^{\circ} \mathcal{N}$ to the fixed southern-tip position at $45^{\circ} \mathcal{N}$.

$6000 \mathrm{~m}$. Figure 3 shows the response of the global annual mean temperature. It increases linearly with maximum height. This is expected since, according to Equation (8), the outgoing long-wave radiation decreases linearly with height. A difference in the maximum height of $1000 \mathrm{~m}$ corresponds roughly to a difference in global annual mean temperature of $0.3^{\circ} \mathrm{C}$.

\subsection{Varying southern-tip position}

In the second sensitivity experiment, the maximum height of the ice sheet is taken to be $h_{0}=85 \sqrt{R / 1000} \mathrm{~m}$ (Pollard, 1983). The ice sheet extends from $72^{\circ} \mathrm{N}$ to the southern-tip position which is varied. The result of this experiment is shown in Figure 4, in which the global annual mean temperature is plotted against the southern-tip position. There is a general decrease of the global annual mean temperature with an increase of the ice-sheet size. This decrease is much stronger, if the ice sheet is given zero height, such that the negative temperature-elevation feedback in Equation (8) is suppressed. For an ice sheet with a southern-tip position at $45^{\circ} \mathrm{N}$, the difference in the temperature response amounts to about $1.0^{\circ} \mathrm{C}$.

\section{DISGUSSION}

An energy-balance climate model has been described which represents the vertically integrated atmosphereocean system. To couple it to an ice-sheet model, it has been combined with a simple parameterization of the hydrological cycle. The model includes seasonal variation and land-ocean contrast. In fact, the effective-heat capacity and co-albedo fields can be specified arbitrarily. When the present, linear version of the model is coupled to an ice-sheet model, the resultant model will include both the ice-sheet-albedo feed-back and the temperatureelevation feed-back, but it will not contain the sea-icealbedo feed-back since the sea-ice extent is not allowed to vary with temperature. This and other feed-backs, which seem to be essential for the build-up and retreat of ice sheets, are to be incorporated into future non-linear versions of the model.

First sensitivity experiments indicate that the energybalance climate model is indeed economical and easy to understand. On an IBM RS/6000 3AT, the CPU time

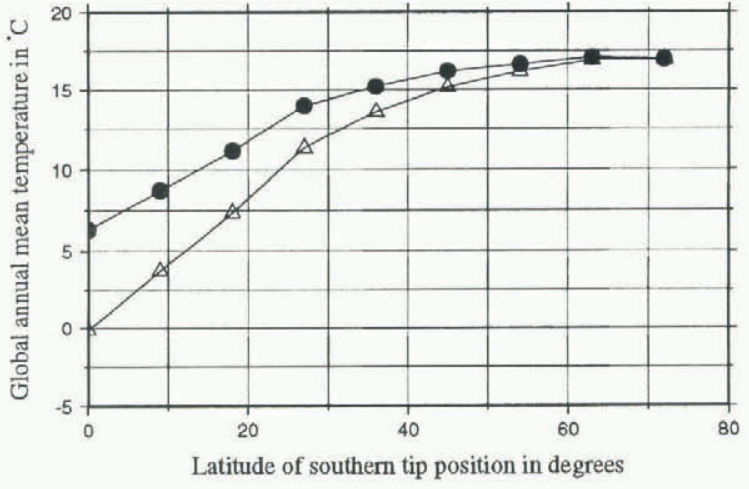

Fig. 4. Global annual mean sea-level temperature versus ice-sheet size. The ice sheet extends from $72^{\circ} \mathcal{N}$ to the southern-tip position. Open triangles: the elevationtemperature effect is suppressed. Solid circles: the elevationtemperature effect is included.

required is as follows: using the T16 (T 11 ) truncation, the intial set-up of the model requires $56 \mathrm{~s}(9 \mathrm{~s})$, while the solution for a particular seasonal cycle of sea-level temperature only takes $1.7 \mathrm{~s}(0.4 \mathrm{~s})$. However, a matrix of size $765 \times 765(390 \times 390)$, which is fairly large, must be inverted and held in memory.

\section{AGKNOWLEDGEMENTS}

I should like to thank A. Manschke, K. Herterich, U. Wyputta and T. Payne for useful comments and valuable advice. I acknowledge the support by the Deutsche Forschungsgemeinschaft - this is Contribution No. 114 of the Sonderforschungsbereich 261 at the University of Bremen.

\section{REFERENCES}

Belousov, S. L. 1962. Tables of normalized associated Legendre polynomials. New York, etc., Pergamon Press. (Mathematical Tables Series 18.)

Berger, A. 1978. Long-term variations of daily insolation and Quaternary climatic changes. f. Atmos. Sci., 35(12), 23622367.

Bowman, K.P. 1982. Sensitivity of an annual mean diffusive energy balance model with an ice sheet. J. Geophys. Res., 87 (C12), 9667-9674.

Bowman, K. P. 1985. Sensitivity of an energy balance climate model with predicted snowfall rates. Tellus, Ser.A, 37(3), 233- 248.

Budyko, M.I. 1969. The effect of solar radiation variations on the climate of the Earth. Tellus, 21(5), 611-619.

Chen. D.. R. Gerdes and G. Lohmann. 1993. A 1-D energy balance atmospheric model applied to ocean modeling. Berichte aus dem Fachbereich Physik 44.

Deblonde, G. and W.R. Peltier. 1991. Simulations of continental ice sheet growth over the last glacial-interglacial cycle: experiments with a one-level seasonal energy balance model including realistic geography. J. Geophys. Res., 96 D5), 9189-9215.

Esch, M.B. and K. Herterich. 1990. A two-dimensional coupled atmosphere ice-sheet continent model designed for paleoclimatic simulations. Ann. Glaciol., 14, 55-57.

Graves, C. E., W.-H. Lee and G. R. North. 1993. New parameterizations and sensitivities for simple climate models. 7. Geophys. Res., 98 D3), 5025-5036.

Hyde, W. T., T.J. Crowley, K.-Y. Kim and G. R. North. 1989. Comparison of GCM and energy balance model simulations of seasonal temperature changes over the past 18,000 years. J. Climate. $28), 864887$

Jentsch, V. 1991. An energy balance climate model with hydrological cycle: 1 . Model description and sensitivity to internal parameters. $\mathcal{J}$. Geophys. Res., 96 D9), 17,169-17,179. 
Paul: Seasonal energy-balance climate model for coupling to ice-sheet models

Machenhauer, B. 1979. The spectral method. In. Numerical methods used in atmospheric model. Vol.II. Geneva, World Meteorological Organization, 121-275. (GARP Publication Series 17.

Messiah, A. 1962. Quantum mechanics. Amsterdam, North-Holland Publishing Co.

North, G. R. and J. A. Coakley. 1979. Differences between seasonal and mean annual energy balance model calculations of climate and climate sensitivity. f. Atmos, Sci., 36 (1), I189-1204.

North, G. R., R. F. Cahalan and J. A. Coakley, Jr, 1981. Energy balance climate models. Rev. Geophys. Space Phys., 19 1), 91-121.

North, G. R., J.G. Mengel and D. A. Short. 1983. Simple energy balance model resolving the seasons and the continents: application to the astronomical theory of the ice ages. .7. Geophys. Res., 88 C11), $6576-6586$.

Pollard, D. 1983. A coupled climate-ice sheet model applied to the Quaternary ice ages. f. Geophys. Res., 88 C12), 7705-7718.

Press, W.H., B.P. Flannery, S.A. Teukolsky and W. T. Vetterling. 1992. Numerical recipes in FORTRA.N: the art of scientific computing. Second edition. Cambridge, Cambridge University Press.

Roeckner, E. and 13 others. 1992. Simulation of the present-day climate with the ECHAM model: impact of model physics and resolution. Hamburg, MaxPlanck-Institut für Meteorologie. (Report 93.

Sanberg, J. A. M. and J. Oerlemans. 1983. Modelling of Pleistocene European ice sheets: the effect of upslope precipitation. Geol. Mijnbouw, 62, 267273.

Schulten, K. and R. G. Gordon. 1975. Exact recursive evaluation of $3 \mathrm{j}$ and $6 \mathrm{j}$-coefficients for quantum-mechanical coupling of angular momenta. J. Math. Phys., 16, 1961-1970.

Schulten, K. and R. G. Gordon. 1976. Recursive evaluation of $3 \mathrm{j}$ and $6 \mathrm{j}$ coefficients. Comput. Phys. Commun., 11, 269278.

Taylor, K.E. 1984. Fourier representation of orbitally induced perturbations in seasonal insolation. In Berger, A., J. Imbrie, J. Hays, G. Kukla and B. Saltzman, eds. Milankovitch and climate: understanding the response to astronomical forcing. Part 1 . Dordrecht, etc., D. Reidel Publishing Co., 113-125. NATO ASI Series C: Mathematical and Physical Sciences 126.)

Washington, W. M. and C. L. Parkinson. 1986. An introduction to threedimensional climate modeling. Mill Valley, CA, University Science Books.

\section{APPENDIX A}

\section{FOURIER-LEGENDRE AMPLITUDES OF DAILY INSOLATION}

Since the daily insolation is azimuthally symmetric, it can be represented by a truncated Fourier-Legendre series. Expressed in terms of real sines and cosines and ordinary Legendre polynomials, the distribution function $S(\mu, t)$ then reads

$$
\begin{aligned}
& S(\mu, t)= \\
& \quad \sum_{l=0}^{L}\left[\frac{a_{l 0}}{2}+\sum_{n=0}^{N}\left(a_{l n} \cos 2 \pi n t+b_{l k} \sin 2 \pi n t\right)\right] P_{l}(\mu) .
\end{aligned}
$$

As outlined by North and Coakley (1979), the FourierLegendre amplitudes $a_{l n}$ and $b_{l n}$ can be computed analytically; North and others (1981) provided them up to $L=2$ and $N=1$. In order to resolve better the high latitudes where there is a long polar night or a long polar day, it is desirable to truncate the series at a higher level. It is found that the series expansion converges everywhere except on the boundary between latitudes where there is daily sunrise and sunset and latitudes where there is a long polar night or day. On this boundary, it converges only asymptotically. In this Appendix, the Fourier Legendre amplitudes up to $L=16$ and $N=4$ are presented.
Table 2. Non-zero Fourier-Legendre amplitudes of daily insolation for a circular orbit

\begin{tabular}{rrrr}
\hline$l$ & $n$ & $\alpha_{l n}^{(0)}$ & $\alpha_{l n}^{(1)}$ \\
\hline 0 & 0 & $0.200006937712830 \mathrm{E}+01$ & $0.727942758418422 \mathrm{E}-05$ \\
0 & 2 & $0.400237880620236 \mathrm{E}-04$ & $0.405864863738902 \mathrm{E}-05$ \\
0 & 4 & $0.384008880692430 \mathrm{E}-05$ & $0.219833378589675 \mathrm{E}-06$ \\
0 & 6 & $-0.105708020960206 \mathrm{E}-05$ & $-0.143008071882862 \mathrm{E}-06$ \\
1 & 1 & $-0.795897262615221 \mathrm{E}+00$ & $-0.320235698738689 \mathrm{E}-01$ \\
2 & 0 & $-0.952798892747514 \mathrm{E}+00$ & $0.239170534814404 \mathrm{E}-01$ \\
2 & 2 & $0.148612104737919 \mathrm{E}+00$ & $0.119579970963495 \mathrm{E}-01$ \\
2 & 4 & $0.327263318824749 \mathrm{E}-05$ & $-0.158599691090462 \mathrm{E}-05$ \\
2 & 6 & $-0.579408398811024 \mathrm{E}-05$ & $-0.713927156439525 \mathrm{E}-06$ \\
4 & 0 & $-0.891806294999281 \mathrm{E}-01$ & $0.129534856100613 \mathrm{E}-01$ \\
4 & 2 & $0.908660546839573 \mathrm{E}-01$ & $0.564134725247211 \mathrm{E}-02$ \\
4 & 4 & $-0.518297314541085 \mathrm{E}-02$ & $-0.836626644588256 \mathrm{E}-03$ \\
4 & 6 & $-0.862737752502799 \mathrm{E}-05$ & $-0.379406997768469 \mathrm{E}-06$ \\
6 & 0 & $0.161700415839655 \mathrm{E}-01$ & $0.659397757505650 \mathrm{E}-02$ \\
6 & 2 & $0.607569895483279 \mathrm{E}-01$ & $0.170476437752998 \mathrm{E}-02$ \\
6 & 4 & $-0.104497133305928 \mathrm{E}-01$ & $-0.150263816064308 \mathrm{E}-02$ \\
6 & 6 & $0.365173904060323 \mathrm{E}-03$ & $0.910140949910895 \mathrm{E}-04$ \\
8 & 0 & $0.274670440259754 \mathrm{E}-01$ & $0.156219728852043 \mathrm{E}-02$ \\
8 & 2 & $0.344338960738196 \mathrm{E}-01$ & $-0.120875401071182 \mathrm{E}-02$ \\
8 & 4 & $-0.142793513326073 \mathrm{E}-01$ & $-0.168154032492723 \mathrm{E}-02$ \\
8 & 6 & $0.131672740464584 \mathrm{E}-02$ & $0.298747109595551 \mathrm{E}-03$ \\
10 & 0 & $0.169206966017579 \mathrm{E}-01$ & $-0.150026652105335 \mathrm{E}-02$ \\
10 & 2 & $0.136574240909285 \mathrm{E}-01$ & $-0.259930152272144 \mathrm{E}-02$ \\
10 & 4 & $-0.153450099424626 \mathrm{E}-01$ & $-0.122866099620399 \mathrm{E}-02$ \\
10 & 6 & $0.279707792567078 \mathrm{E}-02$ & $0.565758380696060 \mathrm{E}-03$ \\
12 & 0 & $0.438844019404613 \mathrm{E}-02$ & $-0.241048167951194 \mathrm{E}-02$ \\
12 & 2 & $0.379162634333408 \mathrm{E}-03$ & $-0.244099350983031 \mathrm{E}-02$ \\
12 & 4 & $-0.133730749218794 \mathrm{E}-01$ & $-0.319199411707478 \mathrm{E}-03$ \\
12 & 6 & $0.444329301059370 \mathrm{E}-02$ & $0.760429595640364 \mathrm{E}-03$ \\
14 & 0 & $-0.320325695203605 \mathrm{E}-02$ & $-0.171347627984590 \mathrm{E}-02$ \\
14 & 2 & $-0.543088446402534 \mathrm{E}-02$ & $-0.127644422488071 \mathrm{E}-02$ \\
14 & 4 & $-0.919778613631028 \mathrm{E}-02$ & $0.640909277871103 \mathrm{E}-03$ \\
14 & 6 & $0.570103239957716 \mathrm{E}-02$ & $0.744916837095426 \mathrm{E}-03$ \\
16 & 0 & $-0.520660985852039 \mathrm{E}-02$ & $-0.382322464746662 \mathrm{E}-03$ \\
16 & 2 & $-0.565836490753235 \mathrm{E}-02$ & $0.730153093586380 \mathrm{E}-04$ \\
16 & 4 & $-0.433278564876693 \mathrm{E}-02$ & $0.122568561865220 \mathrm{E}-02$ \\
16 & 6 & $0.606691359814282 \mathrm{E}-02$ & $0.458375110159306 \mathrm{E}-03$
\end{tabular}

In general, the distribution function $S(\mu, t)$ depends on the orbital elements eccentricity $e$, longitude of perihelion $\tilde{\omega}$ and obliquity $\epsilon$ (Berger, 1978) and so do the Fourier-Legendre amplitudes $a_{l n}$ and $b_{l n}$. But, for a circular orbit, the only dependence is on obliquity $\epsilon$. Furthermore, taking the true longitude of the Earth to be zero at the winter solstice, all sine coefficients vanish (cf. Taylor, 1984). Hence, in this particularly simple case, the Fourier-Legendre representation is

$$
\bar{S}(\mu, t)=\sum_{l=0}^{L}\left[\frac{\alpha_{l 0}}{2}+\sum_{n=0}^{N} \alpha_{l n} \cos 2 \pi n t\right] P_{l}(\mu),
$$

where all remaining non-zero amplitudes are given by

$$
\alpha_{l n}(\epsilon) \approx \alpha_{l n}^{(0)}+\alpha_{l n}^{(1)}\left(\epsilon-\epsilon_{0}\right)
$$

and Table 2. Here, $\epsilon_{0}=23.45^{\circ}$ is the present-day obliquity. The amplitudes for a general orbit can be 
obtained from the formulas

$$
\begin{aligned}
a_{l n}(e, \tilde{\omega}, \epsilon)= & \alpha_{l n}(\epsilon)+n e \cos \tilde{\omega}\left[\alpha_{l, n-1}(\epsilon)-\alpha_{l, n+1}(\epsilon)\right] \\
& +n^{2} e^{2}\left\{\left[\alpha_{l, n-1}(\epsilon)-2 \alpha_{l n}(\epsilon)+\alpha_{l, n+1}(\epsilon)\right]\right. \\
& +\left(\frac{1}{2}\right) \cos 2 \tilde{\omega}\left[\alpha_{l, n-2}(\epsilon)-2 \alpha_{l, n-1}(\epsilon)\right. \\
& \left.\left.+2 \alpha_{l n}(\epsilon)-2 \alpha_{l, n+1}(\epsilon)+\alpha_{l, n+2}(\epsilon)\right]\right\}
\end{aligned}
$$

and

$$
\begin{aligned}
b_{l n}(e, \tilde{\omega}, \epsilon)= & n e \sin \tilde{\omega}\left[\alpha_{l, n-1}(\epsilon)-2 \alpha_{l n}(\epsilon)+\alpha_{l, n+1}(\epsilon)\right] \\
& +\frac{n^{2} e^{2}}{2} \sin 2 \tilde{\omega}\left[\alpha_{l, n-2}(\epsilon)-2 \alpha_{l, n-1}(\epsilon)\right. \\
& \left.+2 \alpha_{l, n+1}(\epsilon)-\alpha_{l, n+2}(\epsilon)\right] .
\end{aligned}
$$

These formulae are similar to those obtained by Taylor (1984) but include the terms in $e^{2}$ which are required for $n>2$. If $n=0$, the n $a_{l n}(e, \tilde{\omega}, \epsilon)=\alpha_{l n}(\epsilon)$ a n d $b_{l n}(e, \tilde{\omega}, \epsilon)=0$. Finally, the complex-mode amplitudes $S_{l 0}^{n}$ are given by

$$
\begin{aligned}
& S_{l 0}^{n}=\sqrt{\frac{2}{2 l+1}}\left(\frac{a_{l|n|}+i b_{l|n|}}{2}\right), \text { if } n>0, \\
& S_{l 0}^{n}=\sqrt{\frac{2}{2 l+1}}\left(\frac{a_{l|n|}-i b_{l|n|}}{2}\right), \text { if } n<0 .
\end{aligned}
$$

\section{APPENDIX B}

\section{GOUPLING COEFFICIENTS FOR SPECTRAL MODES}

In contrast to the spectral transform method (Machen- hauer, 1979), the multiplication of two fields is also carried out in spectral space. For example, on the lefthand side of Equation (2.1), the product of temperature $T$ and effective heat capacity $C$ is represented by

$$
\begin{aligned}
T C= & \sum_{l_{1}, m_{1}} \sum_{l_{2}=l_{2, \min }}^{l_{2, \max }} i 2 \pi\left(n_{1}+n_{2}\right) G_{l_{1} l_{2} l}^{m_{1}, m-m_{1}, m} \\
& \times T_{l_{1} m_{1}}^{n_{1}} C_{l_{2}, m-m_{1}}^{n-n_{1}} Y_{l m}(\lambda, \mu) \exp (i 2 \pi n t)
\end{aligned}
$$

where $l_{2, \min }=\max \left(\left|l-l_{1}\right|, m_{2}\right)$ and $l_{2, \max }=l+l_{1}$. Here, the coupling coefficients $G_{l_{1} l_{2} l}^{m_{1} m_{2} m}$ are defined by

$$
G_{l_{1} l_{2} l}^{m_{1} m_{2} m}=\frac{1}{2 \pi} \int Y_{l_{1} m_{1}} Y_{l_{2} m_{2}} Y_{l,-m} \mathrm{~d} \Omega .
$$

Now, the integral involving three spherical harmonics can be expressed in terms of Wigner $3 \mathrm{j}$ symbols

$$
\left(\begin{array}{ccc}
l_{1} & l_{2} & l \\
m_{1} & m_{2} & m
\end{array}\right)
$$

or, equivalently, in terms of Clebsch-Gordon coefficients (Messiah, 1962). Using Wigner $3 \mathrm{j}$ symbols, they read

$$
\begin{aligned}
G_{l_{1} l_{2} l}^{m_{1} m_{2} m}= & 2 \pi\left[\frac{\left(2 l_{1}+1\right)\left(2 l_{2}+1\right)(2 l+1)}{2}\right]^{\frac{1}{2}} \\
& \times\left(\begin{array}{lll}
l_{1} & l_{2} & l \\
0 & 0 & 0
\end{array}\right)\left(\begin{array}{ccc}
l_{1} & l_{2} & l \\
m_{1} & m_{2} & m
\end{array}\right) .
\end{aligned}
$$

For a recursive evaluation of the Wigner $3 \mathrm{j}$ symbols, a modified version of the algorithm by Schulten and Gordon $(1975,1976)$ is used. This algorithm is, at the same time, efficient and accurate even for large wave numbers. 